\title{
Multimodal literacy: Unfolding reading path in children's picture book and its potential for EFL classrooms
}

\author{
Ika Lestari Damayanti ${ }^{{ }^{*}}$ and Yusnita Febrianti ${ }^{2}$ \\ ${ }^{1}$ Department of English Education, Faculty of Language and Literature Education, Universitas Pendidikan Indonesia, \\ Jalan Dr. Setiabudhi No. 229 Bandung, West Java, Indonesia \\ ${ }^{2}$ Department of Literature, Faculty of Letters, Universitas Negeri Malang, Jl. Semarang No. 5 Malang 65145,
} East Java, Indonesia

\begin{tabular}{|c|}
\hline $\begin{array}{l}\text { ABSTRACT } \\
\text { This paper reports on an investigation into the reading path patterns in a children's picture book. } \\
\text { The primary investigation focused on the semiotic resources involved in the construction of } \\
\text { meanings in picture books, i.e. language and image elements. These semiotic resources provide } \\
\text { insights into the unfolding of the storylines in the observed picture book. In order to detail the } \\
\text { roles of these resources, a picture book entitled Tacky the Penguin (Lester, 1988) was selected } \\
\text { and examined by employing two methods: Kress and van Leeuwen's (1996, 2006) structure of } \\
\text { information value and Royce's (1998) Intersemiotic Complementarity. The results of the } \\
\text { analysis suggest that the whole picture book is built from a page-by-page reading path that } \\
\text { allows for a linear and non-linear reading path. While each page presents a different layout of } \\
\text { information value, the general pattern leads to a linear reading path from the beginning up to the } \\
\text { end of the picture book. The mapping of the reading path is reinforced by the interrelated } \\
\text { meanings between verbal and visual resources on the page. Drawing on the analysis results, this } \\
\text { paper offers the delve into the flow of information from the language and image resources in the } \\
\text { picture books that can be used to informpractical use of picture books in EFL classrooms. } \\
\text { Keywor ds: Intersemiosis; multimodal literacy; picture books; reading path; verbal; visual } \\
\text { resources }\end{array}$ \\
\hline $\begin{array}{lc}\text { First Received: } & \text { Revised: } \\
18 \text { October } 2019 & 30 \text { November } 2019 \\
\text { Final Proof Received: } & \\
\text { 27 January 2020 } & \end{array}$ \\
\hline $\begin{array}{l}\text { How to cite (in APA style): } \\
\text { Damayanti, I. L. \& Febrianti, Y. (2020). Multimodal literacy: Unfolding reading path in } \\
\text { children's picture book and its potential for EFL classrooms. Indonesian Journal of } \\
\text { Applied Linguistics, 9, 616-627. doi: } 10.17509 / \mathrm{ijal} . \mathrm{v} 9 \mathrm{i} 3.23212\end{array}$ \\
\hline
\end{tabular}

\section{INTRODUCTION}

Multimodal literacy has gained more attention amongst literacy educators, researchers and curriculum authorities (Unsworth, Cope, \& Nicholls, 2019; Damayanti, 2014; Hermawan \& Sukyadi, 2017). As students' interactions with multimodal texts in recent years are increasingly pervasive, the focus of literacy in school can no longer be limited to reading and writing of printed texts such as the school textbooks. Instead, students need to be supported in making meanings from multimodal texts that range from the integration of images and language (e.g. picture books) to online and virtual settings (e.g., social media, website, wikis).

In the context of teaching English as a foreign language (EFL), picture books have been widely used to assist children's language learning. Images, which are typically rich in picture books, are usually used to help students identify new lexical items as it provides context to create meaning (Lee, 2015; Mourão, 2016; Oe \& Alam, 2013, Sun, 2015). While images tend to be treated as 'addition' to words, meaning-making in picture books is dependen

$\mathrm{t}$ upon pictures and words together (Unsworth et al., 2019). Using picture books in EFL classrooms, thus, entails the necessity for EFL teachers to be concerned with developing their own as well as their students' multimodal literacy. Accessing multimodal texts, such as picture books, requires competences in interpreting meanings derived from both visual and verbal resources. In response to the need for developing multimodal

\footnotetext{
* Corresponding Author

Email: ikalestaridamayanti@upi.edu
} 
literacy, the study reported on this paper investigated reading path patterns to map the flow of information emanated from the language and image resources in the picture books as well as the potential of its usefulness for practical use in EFL classrooms.

\section{Conceptual review}

The present study is built upon two theoretical concepts derived from Systemic Functional Linguistics (SFL) theory: (1) intersemiotic complementarity developed by Royce (1998) and (2) compositional meanings in visual design developed by Kress and van Leeuwen (1996, 2006). These conceptual theories are primarily related to the main objective of the study, i.e., mapping a reading path in children's book.

The reading path is defined as the order and direction in which the reader approaches the text or images on the page (O'Halloran, Marissa, Podlasov \& Tan, 2013). Then, the prescribed reading path is divided into two categories, namely linear and non-linear reading paths. In a linear reading path, the reader engages with the text in a linear and sequential order. In western societies, linear texts are usually read from leftto-right and top-to-bottom. Linear texts are 'unidirectional' or 'closed' texts. The reading path is determined by the author of the page. A typical example of a linear text is a newspaper article without pictures. On the other hand, in the non-linear reading path, the reader engages with the text in non-linear and nonsequential order. Non-linear texts are 'multi-directional' or 'open' texts. The reading path is determined by the reader. A typical example of a non-linear text is an internet web-page. Picture books sit on the continuum of linear and non-linear texts as meanings are co-created between texts and images. While the reading path of verbal elements tends to be determined by authors of the story, picture books' readers can engage with the images in a non-linear way.

\section{Intersemiotic Complementarity}

Picture books deliver their message via two primary semiotic resources: language and image. In the meaning-making interpretation, therefore, it is pivotal to identify the relationships between both resources in making meanings. In this study, the formulation of Intersemiotic Complementarity (Royce, 1998, 2007a, $2007 \mathrm{~b})$ is used to understand language-image relationships. Royce (1998; 2007a; 2007b) offers Intersemiotic Complementarity as a framework for multimodal analysis that can help EFL teachers develop their students' multimodal literacies and design a pedagogical metalanguage to assist the learning. This framework is an extension of Halliday's Systemic Functional Linguistics (SFL) theory that emphasises the critical role of social contexts in the construction and interpretation of meaning (Halliday \& Hasan, 1985; Halliday \& Matthiessen, 2014).

In SFL theory, meaning resources are organised into three components of metafunction: the ideational, the interpersonal, and the textual. The ideational metafunction represents our experience of the world (e.g. doing, thinking, relating things, etc.) involving various processes, participants, and circumstances. The interpersonal meaning expresses our relationships with others, our attitudes and opinion. The textual meaning creates a coherent and cohesive text that makes sense in their contexts of situation. In consonance with it, Royce (2007b, p. 66) refers to the visual metafunctions as the ideational-representational meaning, the interpersonalinteractive meaning, and the textual-compositional meaning. Royce (2007b) argues that focus on ideational intersemiotic complementarity may well assist EFL learners in extracting informational content, which is commonly present in their English language learning materials. This paper, therefore, examines the ideational intersemiotic complementarity represented in a picture book by using Royce's (1998) framework presented in Table 1.

The starting point for ideational intersemiotic analysis is the identification of the verbal meanings; each clause is analysed in terms of its Transitivity features, which include the processes (what is happening), participants (who/what is involved), and circumstances (additional information related to where, when, how). The next step is to identify the visual message elements (VMEs) of the represented participants (what Royce terms as 'Identification'), the represented activities, the represented circumstances, and the attributes of the participants. The identified VMEs are then grouped into lexical inventories which are collated with the verbal items to examine any similar or differentiated meanings. In examining these semantic relationships, Royce (1998) suggests the use of Halliday and Hasan's analysis of cohesion in a text such as Repetition (R), Synonymy (S), Antonymy (A), Hyponymy (H), Meronymy (M), and Collocation (C).

In addition to Royce's (1998) framework, the visual ideational meanings are also analysed using Kress and van Leeuwen's (2006) narrative representation. It is used to examine the ways images represent our experiences of the world through the identification of lines or 'vectors' that emanate from participants or other elements in the image. Table 2 presents Kress and van Leeuwen's (2006) visual ideational meanings.

\section{Compositional meanings}

The basic concept of the understanding of compositions in a static or page-based multimodal image is developed by Kress and van Leeuwen (1996, 2006). Compositional patterns in a page-based multimodal text are described as the overall composition wherein the representational and interactive elements are made to relate to each other to integrate into a meaningful whole (Kress \& van Leeuwen, 2006, p. 176). These functions are related to each other through three interrelated systems of information value, salience and framing. Information value deals with the values attached to the various zones on a page. Figure 1 illustrates the various zones that include left-right, top-bottom and central-margin. 
Salience concerns with the element of an image that makes it stand out as a visual element. Framing concerns with the disconnection and connection between the image and its surrounding through the presence or absence of frames.

Table 1. Ideational-representational Intersemiotic Complementarity

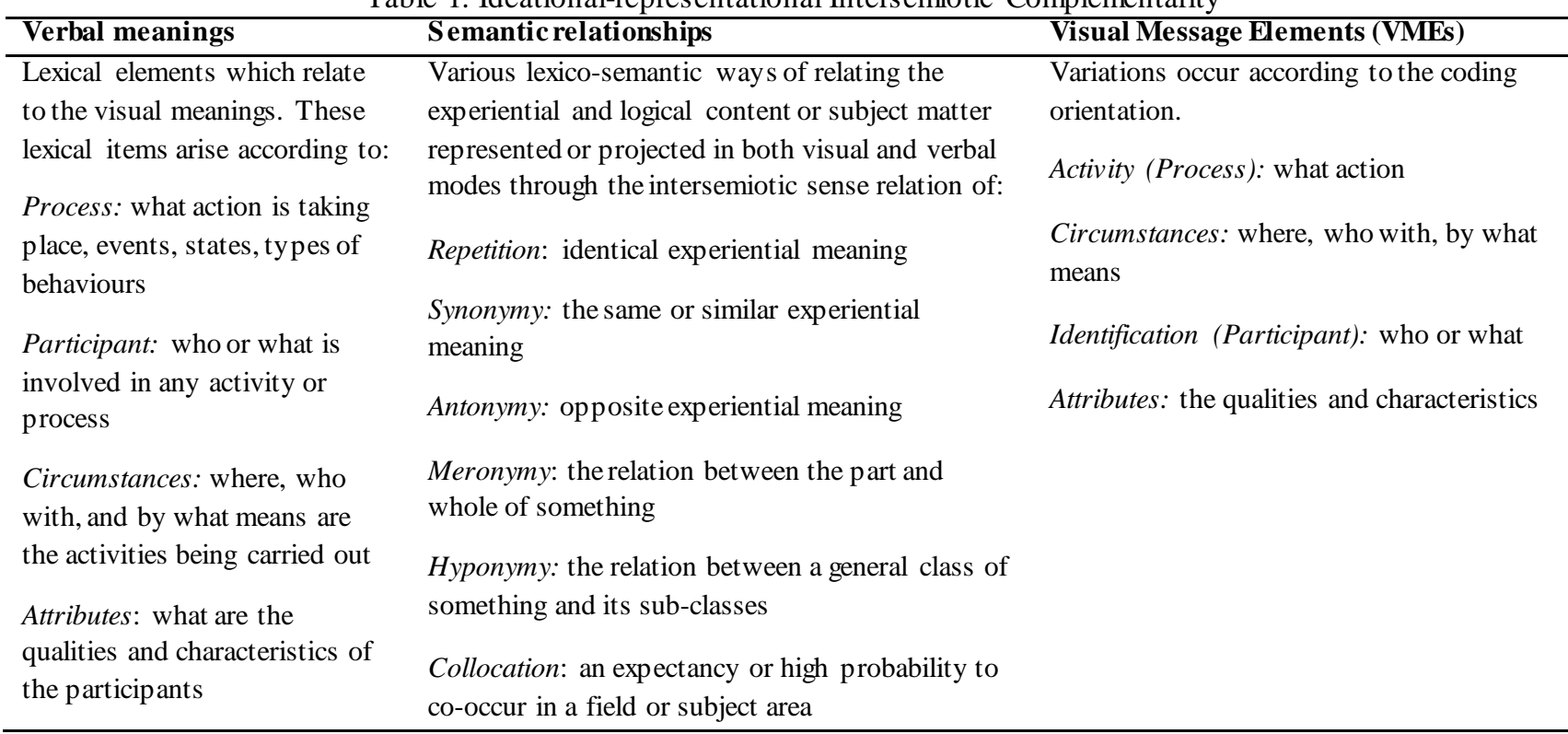

Table 2. Kress and van Leeuwen's (2006) visual ideational meanings

\begin{tabular}{|c|c|c|}
\hline & Visual Processes & Participant roles \\
\hline \multirow[t]{3}{*}{ Action } & Transactional: & Transactional \\
\hline & $\begin{array}{l}\text { a. Unidirectional: a vector connects two participants } \\
\text { b. Bidirectional: s vector connects two participants where the vector } \\
\text { could be said to emanate from and be directed, at both participants }\end{array}$ & $\begin{array}{l}\text { a. Unidirectional: Actor-Goal } \\
\text { b. Bidirectional: Interactor }\end{array}$ \\
\hline & $\begin{array}{l}\text { Non-transactional: a vector which emanates from a participant is not 'done } \\
\text { to' or 'aimed at' anyone or anything, it represents events }\end{array}$ & $\begin{array}{l}\text { Non-transactional action: Actor-- } \\
\text { no Goal }\end{array}$ \\
\hline \multirow[t]{2}{*}{ Reactional } & Transactional Reaction: an ey eline vector connects two participants & $\begin{array}{l}\text { Transactional Reaction: Reacter - } \\
\text { Phenomenon }\end{array}$ \\
\hline & $\begin{array}{l}\text { Non-transactional Reaction: an ey eline vector emanates from a participant } \\
\text { but does not point at another particip ant }\end{array}$ & $\begin{array}{l}\text { Non-transactional Reaction: Reacter } \\
\text { - no Phenomenon }\end{array}$ \\
\hline \multirow[t]{2}{*}{ Projective } & $\begin{array}{l}\text { Mental: a vector formed by a 'thought bubble' connects two participants } \\
\text { (i.e. Senser-Phenomenon) }\end{array}$ & Mental: Senser - Phenomenon \\
\hline & $\begin{array}{l}\text { Verbal: a vector formed by a 'speech bubble' connects two participants (i.e. } \\
\text { Sayer-Utterance) }\end{array}$ & Verbal: Sayer - Utterance \\
\hline
\end{tabular}

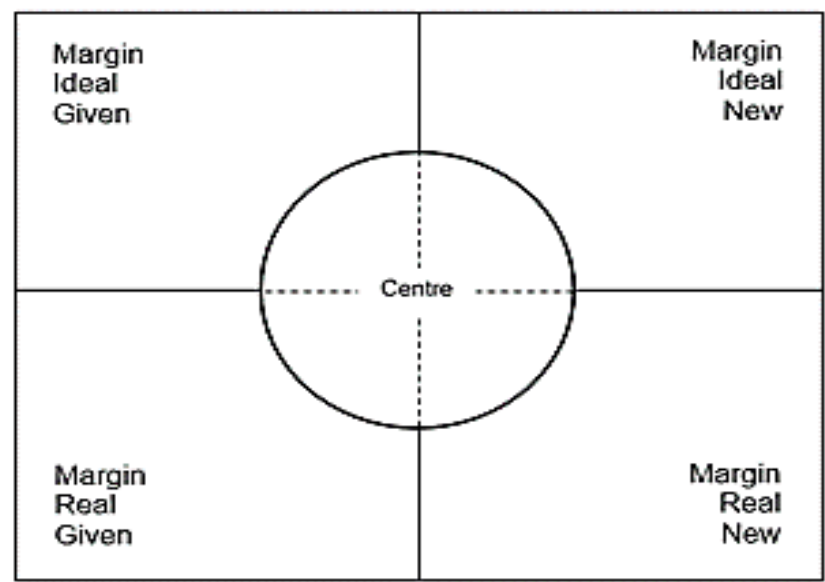

Figure 1. Composition diagram (Kress \& van Leeuwen, 1996, 2006) 


\section{METHOD}

The selection of picture book: Tacky the Penguin

The primary data in this study is the selected pages of a picture book entitled Tacky the Penguin (Lester, 1988). The main narrative in the story centres around a penguin named Tacky. He is introduced as a bird with 'odd' habits different from his friends. The contrast between Tacky and his friends is clearly described from their clothing and demeanour. While other penguins greet politely, march, sing, and dive gracefully, Tacky seems to do all these things just the opposite. However, as the story unfolds, it turns out that Tacky's oddness has saved them all from hunters intending to catch the penguins. Tacky, by being himself, managed to convince the hunters to leave their icy land without catching any penguins.

The transformation of Tacky from an undesirable figure to a hero suggests a moral message of what is inside is more important than the outside. This moral message commonly embodied in picture books (Christie \& Derewianka, 2008; Painter, Martin, \& Unsworth, 2013) could be better understood through the interpretation of both the verbiage and the image. Although there is a mention of Tacky being an outsider in the verbal texts, the visual details add more nuances of separateness between Tacky and his companions.
Hence, supporting students' understanding of this story could be developed not only from the identification of characters and plot structures in the verbal texts but also from the examination of visual representation and visual narrative sequence.

\section{The data sets}

The identification of plot of the story was required to select the analysed pages even though the study did not focus on genre analysis, The data sets of this study comprise two spreads (a double-page) and a page representing the Orientation and Complication stages of the story. These stages were selected as they provide rich development of the story useful for investigating the reading path patterns. Due to the copyright is sue, the corresponding picture book pages are not supplemented in this paper. Instead, graphs and reproduced black and white sketches of the pages or spreads are supplied to visualise the mapping and visual analysis. The three data sets are displayed in Figures $2-$ 4. Figure 2 illustrates a spread that introduces the characters of the story. Figure 3 displays a page that focuses on the characters' activity. Figure 4 illustrates anotherspread that presents an attempted solution made by the main character of the story.

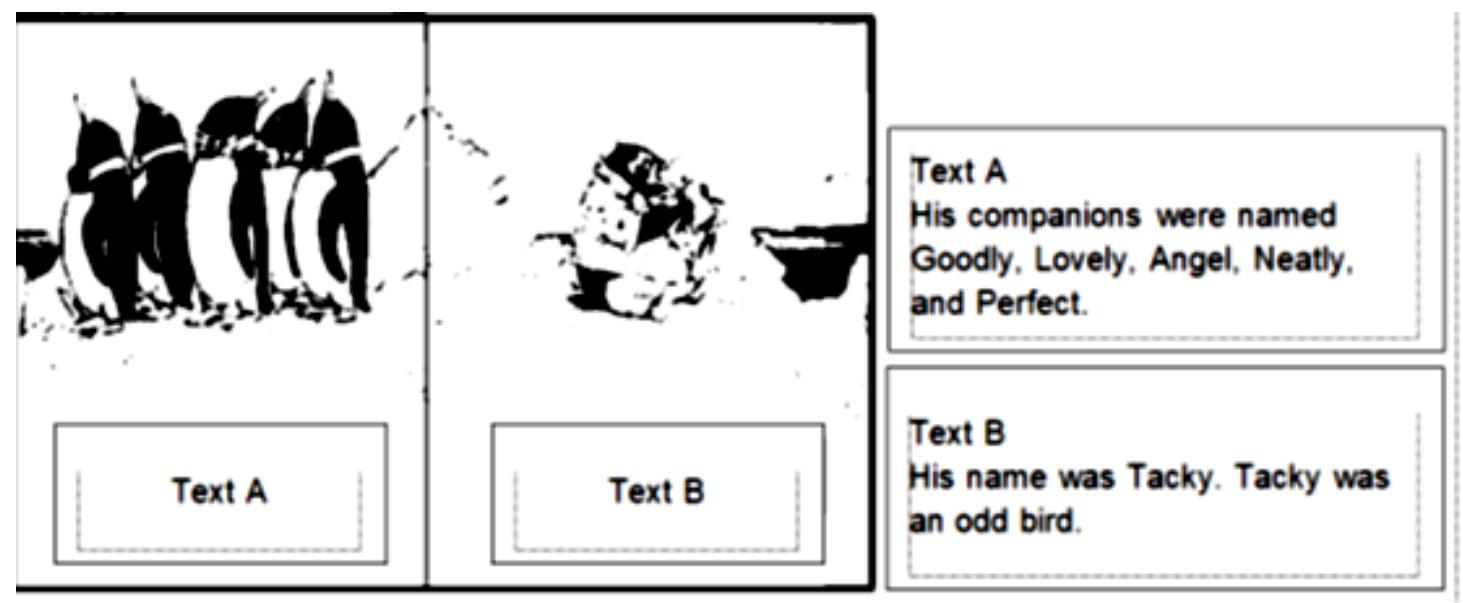

Figure 2. A spread introducing characters (data set 1)

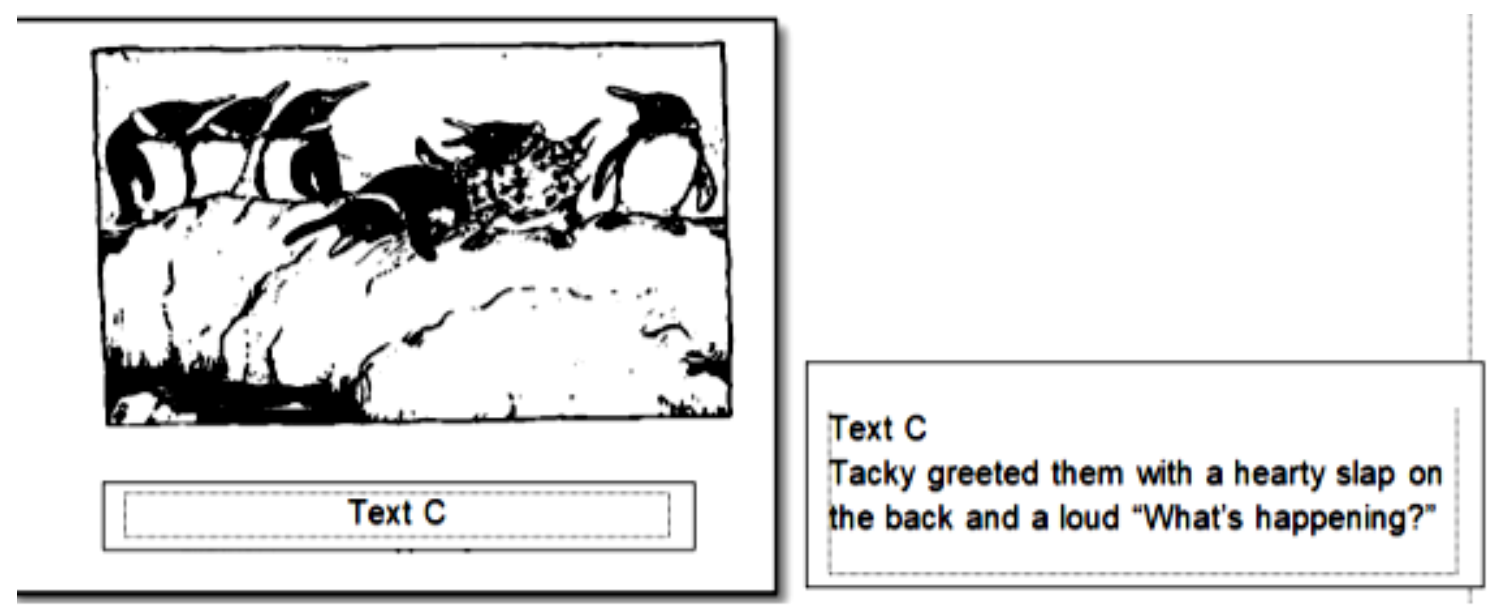

Figure 3 A page presenting the characters' activity (data set 2) 


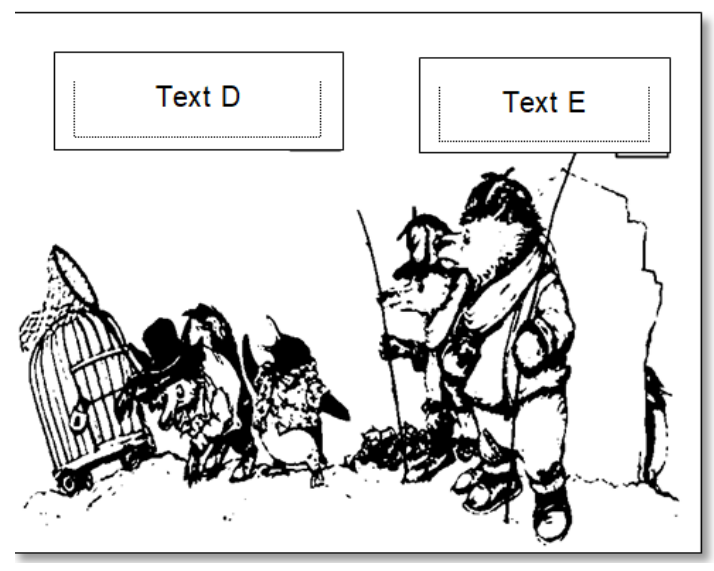

Text D

"What's happening?" blared Tacky, giving one hunter an especially hearty slap on the back.

Figure 4. A spread presenting an attempted solution (data set 3)

\section{Data analysis procedure}

In this study, the process of understanding the content of a picture book is constructed, firstly, by the layout of the language and image content and, secondly, by the interrelation of meanings between language and image in the particular pages or spreads. Both accounts contribute to the construction of the overall reading path of the picture book. Prior to the detailed analys is of the Information Value arrangement and the Intersemiotic Complementarity between the language and image elements on each page, a general observation has been done on the characteristics of the ad hoc selection of Tacky the Penguin.

To unpack the information value and the intersemiosis complementarity relations, the study combines two basic methodologies namely the structure of information value from Kress and van Leeuwen (1996, 2006) and the Intersemiotic Complementarity from Royce (1998). In terms of information value, Kress and van Leeuwen (1996) describe that the placements of elements (participants and syntagms that relate them to each other and to the viewer) endow them with the specific informational values attached to the various 'zones' of the image: left and right, top and bottom, centre and margin. Secondly, the study considers the interrelation between the language and image in the picture book. These relationships are described in Royce's (1998) work as cohesive mechanism realised in Repetition (R), Synonymy (S), Antonymy (A), Hyponymy (H), Meronymy (M), and
Collocation (C) between language and image resources on the same page. At the end of the analysis, an overall mapping of the reading path in the picture book will be drawn. Also, the pedagogical implications of this reading map are formulated for classroom use.

\section{FINDINGS AND DISCUSSION \\ Ideational Intersemiotic Complementarity}

The analysis of ideational intersemiotic complementarity in this paper focuses on the stages in which the contrast of the characters in Tacky the Penguin is established to build and release the tension encountered by the main characters. The story of Tacky the Penguin begins with the introduction of the characters in terms of their identities, locations, and activities. In Figure 2, the identity of the characters is introduced on a double-page spread that depicts a single visual element spanning the two pages and one separated textual element on each page. The texts are annotated in the figure as Text A and Text B. From the verbal texts, the single penguin is identified as 'Tacky' and the other five as 'his companions'. The five penguins are depicted on the verso (left page) looking away from Tacky on the recto (right page).

In terms of verbal elements, each clause in the text blocks (Texts A, B1, and B2) was analysed to identify the ideational meanings. Figure 5 presents the analysis of the first data set as follows.

\begin{tabular}{|c|c|c|}
\hline \multicolumn{3}{|l|}{ Text A } \\
\hline His companions & were named & Goodly, Lovely, Angel, Neatly, and Perfect \\
\hline Token & Process: identifying & Value \\
\hline \multicolumn{3}{|l|}{ Text B1 } \\
\hline His name & was & Tacky \\
\hline Token & Process: identifying & Value \\
\hline \multicolumn{3}{|l|}{ Text B2 } \\
\hline Tacky & was & an odd bird \\
\hline Carrier & Process: attributive & attribute \\
\hline
\end{tabular}

Figure 5. Analysis of verbal elements in the introduction to characters 
The analysis shows that each clause in the text blocks construes the identification of the represented participants. It is interesting to note that the identifying clauses in text A and text B1 name the characters with referents which reflect their qualities. For example, each of the five penguins is named with proper nouns that carry widely-perceived pleasant features such as Lovely and Perfect. On the other hand, the 'different' quality of
Tacky from other penguins is not only identified from its name but also emphasized by a classifying attribute of being 'odd' (clause B2).

Turning to visual elements, this spread includes two main participants, a group of five penguins and Tacky. Table 3 summarises the analysis of visual meanings that focuses on the introduction to characters.

Table 3. Ideational-representation meaning of introduction to characters

\begin{tabular}{|c|c|c|c|}
\hline Elements & Visual Realisations & Visual Transitivity Roles & $\begin{array}{c}\text { Visual Message Elements } \\
\text { (VMEs) }\end{array}$ \\
\hline Identification & Five penguins & Reacter & Tacky's friends \\
\hline Attribute & $\begin{array}{l}\text { Solid-coloured bow ties, false collar, } \\
\text { tidy hair }\end{array}$ & & Conservative values \\
\hline Identification & A penguin & $\begin{array}{l}\text { Phenomenon } \\
\text { Actor }\end{array}$ & Tacky \\
\hline Attribute & $\begin{array}{l}\text { Plaid bow tie, Hawaiian flowery shirt, } \\
\text { wide eyes }\end{array}$ & & An outsider, happy \\
\hline Identification & A fish sandwich & Goal & \\
\hline Activity & Walking in a group & $\begin{array}{l}\text { Non-transactional action } \\
\text { process }\end{array}$ & Majority \\
\hline Activity & Eating a fish sandwich by one's self & Transactional-action process & Comfort \\
\hline Circumstance & $\begin{array}{l}\text { Five penguins are away from Tacky } \\
\text { with chins up and eyes closed, on the } \\
\text { icy land }\end{array}$ & Manner & Superior \\
\hline
\end{tabular}

Vectors emanating from a group of penguins to Tacky realise transactional reaction processes. Although the penguins' bodies facing towards the opposite direction from Tacky and most of the penguins' eyes are closed with their chins up, vectors from one of the penguins' gaze and from beaks of the two penguins in the centre of the group towards Tacky realises a transactional reaction process. It shows that there is an exchange between the five penguins (Reacters) who perceive Tacky (Phenomenon) as the undesirable other. While Tacky is assigned as Phenomenon, Tacky also represents Actor of an action process; that is, he is eating a fish sandwich by himself.

The contrast between these two main characters, Tacky and his friends, is also construed in terms of their attributes. The five penguins with their tidy hair wearing tuxedos, solid-coloured bow ties and false collar blend harmoniously with the environment. Such description makes them all look elegant and conservative. On the contrary, Tacky with his messy hair wearing Hawaiian flowery shirt symbolizes warmth and informality, which is contradictory to the dominant environment of the cold and icy landscape. This description signifies that Tacky is different from the majority.

Bringing the verbal and visual elements together, the analysis of ideational-intersemiotic complementarity indicates that the introduction page in this story provides more information than merely naming the characters. Figure 6 displays the intersemiotic complementarity of introduction to characters.

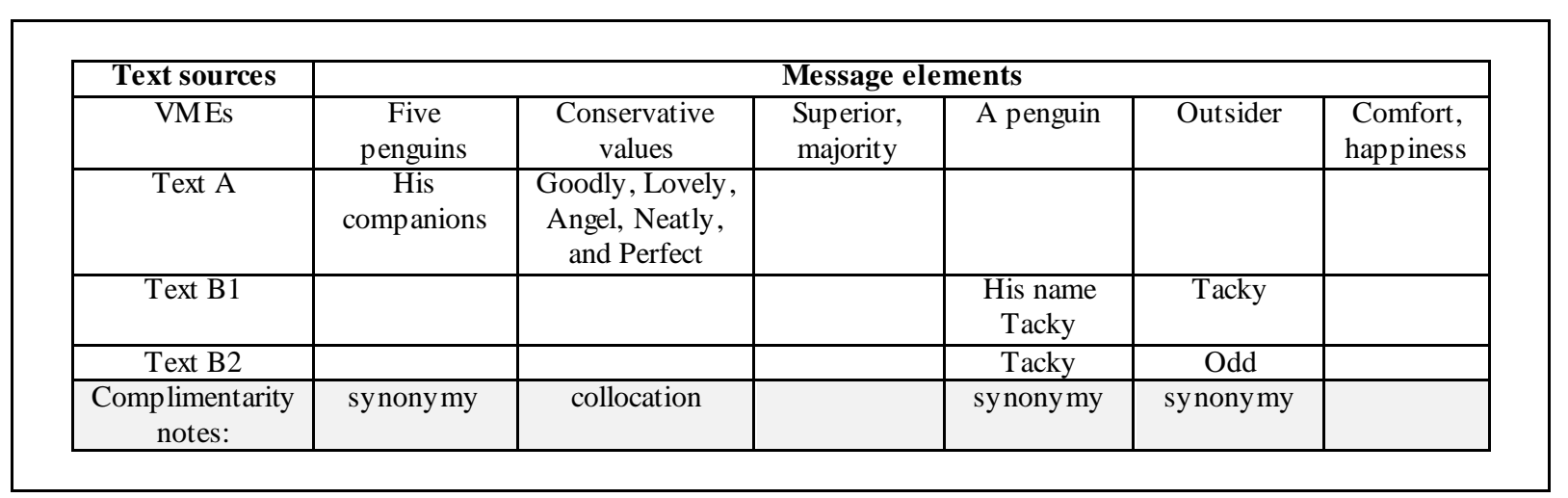

Figure 6. Inters emiotic complementarity of introduction to characters 
As shown in Figure 6, a group of penguins and a single penguin in the image are complemented verbally by the synonym of 'his companions' for the group and 'his name, Tacky' for the single penguin. The attributes assigned to the group are signalled by formal outfits in the visual. They are intersemiotically related to the collocation of their names which carry positive values.

In contrast, the attributes of the main character that is different from the dominant group are signalled in the synonym of the proper name and adjective 'Tacky'. Some elements that are not realised in the verbal texts are the represented activity and circumstance. The realisation of an action process in which Tacky is eating a fish sandwich alone and with his eyes wide open expands the semiotic meaning. That is, despite his being different and excluded from the majority, Tacky remains happy and comfortable. Recognizing such a message is crucial in order to better understand the successive events in which Tacky is presented as an independent and courageous figure.

In addition to introducing the characters, the beginning stage of the story presents the characters' habitual activities. These include the ways the penguins greet. The page that depicts this event was selected as the second data set. On this page, the image is placed on the top of the verbiage. Figure 7 presents the analys is of the verbal elements annotated as Text $\mathrm{C}$.

\begin{tabular}{|c|c|c|c|}
\hline \multicolumn{4}{|l|}{ Text C } \\
\hline Tacky & greeted & them & with a hearty slap on the back and a loud 'What's happening." \\
\hline sayer & Process: verbal & recipients & Circumstance: manner \\
\hline
\end{tabular}

Figure 7. Analysis of the verbal elements in the characters' activity

As shown in Figure 7, text $\mathrm{C}$ is a projective clause in which the participant is involved in a verbal process. Here, the way Tacky greets is not only supplemented by the description of his manner but also with his typical saying.
While the textual element comprises one participant, the image involves more participants: a group of participants and a penguin to whom Tacky greets in his special way. The summary of the visual analysis of the second data set is displayed in Table 4.

Table 4. Ideational-representational meaning of characters' activity

\begin{tabular}{|c|c|c|c|}
\hline Elements & Visual Realisations & Visual Transitivity Roles & Visual Message Elements \\
\hline Identification & $\begin{array}{l}\text { A penguin wearing a Hawaiian flowery shirt } \\
\text { with plaid bow tie }\end{array}$ & Participant: Actor & Tacky \\
\hline Identification & $\begin{array}{l}\text { A penguin who dresses in a uniform way with } \\
\text { other four penguins. He is being acted upon by } \\
\text { a penguin in Hawaiian flowery shirt and almost } \\
\text { fall into the sea. }\end{array}$ & Particip ant: Goal & One of Tacky's friend \\
\hline \multirow[t]{2}{*}{ Identification } & $\begin{array}{l}\text { Four penguins standing in a row; three on the } \\
\text { left-hand side and one on the right. }\end{array}$ & Participant: Reacter & Tacky's four other friends \\
\hline & $\begin{array}{l}\text { In between, there is a penguin slapping on } \\
\text { another penguin's back. }\end{array}$ & Phenomenon & Tacky and a friend \\
\hline Activity & Slapping a penguin's back & Actional process & Slapping on one's back \\
\hline Activity & Wide-open mouth & Verbal process & Saying loudly \\
\hline Activity & $\begin{array}{l}\text { Four penguins with rolling eyes watching a } \\
\text { penguin slapping on another penguin's back }\end{array}$ & Reactional process & $\begin{array}{l}\text { Demeaning reactions from } \\
\text { Tacky's friends }\end{array}$ \\
\hline Circumstance & $\begin{array}{l}\text { On icy land, positioned in the centre of a group } \\
\text { of penguins }\end{array}$ & Circumstance: locative & On icy land \\
\hline
\end{tabular}

As described in Table 4, the focus of attention in the image, illustrating characters' activity is the portrayal of Tacky in the centre with one of his penguin friends. Tacky's slap on one of the penguin's back causes the penguin to almost fall over the edge of the icy land. A line emanating from his limb to the penguin's back creates a transactional action process in which Tacky is the Actor and the penguin the Goal. This event in itself construes as a Phenomenon signalled by the gaze from the other four penguins standing nearby. The penguins' rolled-eyes can also be interpreted as a disapproval look. A verbal process is also present indicated by Tacky's wide-open mouth even though there is no vector provided by a speech bubble (Painter et al., 2013).

In terms of complementarity, the verbal and actional processes in the image have the correspondence in the verbal texts. The summary of the analysis is presented in Figure 8. 
Turning to the third data set, a double-page spread presents an attempted solution to a problem faced by the characters. Before the solution presented on this spread, the change of five penguins' reactions towards Tacky's oddness is presented gradually following the narrative sequence. The superiority of other penguins depicted in the Orientation stage is turned into inferiority in the Complication stage. The inferiority of other penguins comes into existence as a group of hunters is introduced into the scene, which signals disruption to the established status quo of the beautiful icy land. As a response to this problem, a mirroring event in which Tacky gives a hearty slap as his way of greeting people is presented. As a result, these hunters are visually described as being involved in an unexpected situation.

On this spread, the image occupies most of the space from left to right, while the verbiage is placed on the top of the images on each page. The verbal elements are annotated as Text D that consists of two clauses (D1 and D2) and Text E with three clauses (E1, E2, and E3). The analysis of the textual elements that shows an attempted solution is presented in Figure 9.

\begin{tabular}{|c|c|c|c|c|c|}
\hline Text sources & \multicolumn{5}{|c|}{ Message elements } \\
\hline VMEs & Tacky's friends & Tacky & $\begin{array}{l}\text { Slapping on } \\
\text { one's back }\end{array}$ & Saying loudly & Demeaning reactions \\
\hline Text $\mathrm{C}$ & Them & Tacky & $\begin{array}{c}\text { A slap on the } \\
\text { back }\end{array}$ & $\begin{array}{l}\text { Greet with a } \\
\text { loud "what's } \\
\text { happening." }\end{array}$ & \\
\hline $\begin{array}{l}\text { Complimentarity } \\
\text { notes: }\end{array}$ & synonymy & synonymy & repetition & synonymy & \\
\hline
\end{tabular}

Figure 8. Ideational-intersemiotic complementarity of characters' activity

\begin{tabular}{|c|c|c|c|}
\hline \multicolumn{4}{|l|}{ Text D1 } \\
\hline "What's happening?" & blared & Tacky & \\
\hline Verbiage & Process: Verbal & Sayer & \\
\hline \multicolumn{4}{|l|}{ Text D2 } \\
\hline Giving & One hunter & an especially hearty slap & on the back \\
\hline Process: material & recipient & goal & Circumstance: place \\
\hline \multicolumn{4}{|l|}{ Text E1 } \\
\hline They & growled & & \\
\hline Sayer & Process: verbal & & \\
\hline \multicolumn{4}{|l|}{ Text E2 } \\
\hline $\mathrm{We}$ & 're hunting for & penguins & \\
\hline Actor & Process: material & Goal & \\
\hline \multicolumn{4}{|l|}{ Text E3 } \\
\hline \multirow[t]{2}{*}{ That } & 's & what's happening & \\
\hline & Process: relational & & \\
\hline
\end{tabular}

Figure 9. Analysis of the verbal texts in an attempted solution

As introduced in the beginning page, Tacky's unusual way of greeting has made one of the hunters almost fall. The other two hunters who stand nearby are only watching with a baffled look. The analysis presented in Figure 9 shows that two prominent processes identified in this double-page spread are an actional process and reactional processes. In the actional process, Tacky is assigned as the Actor and one hunter as the Goal. A reactional process is created by the other two hunters' gaze towards Tacky. The presence of a birdcage, a trap net, rocks, and long rods held by the hunters who are much bigger than Tacky creates a threatening situation. Despite this situation, Tacky is constantly portrayed as being unreserved and easy.
As far as the visual elements are concerned, this double-page spread presents three groups of images: (1) Tacky giving a slap on a hunter's back (2) two hunters standing and looking at what's Tacky doing and (3) a penguin hiding behind an ice block, see Table 8 for the analysis of visual meanings.

The visual on this spread contributes more to the construction of Tacky's new attribute of being more desirable and his friends' qualities of being inferior. The portrayal of Tacky being brave in dealing with the hunter is signalled from his beak that resembles a megaphone. It is in parallel with the word 'blared' projecting a loud 'what's happening' (text D1). The emphasis on Tacky's new attribute is also supported by the contradictory depiction of the hunters in the image 
and in the verbal texts. The hunters are not visually described as menacing as the word 'growled' (text E1). While most of the space is dedicated to the interaction between Tacky and the hunters, in the background, only one penguin is depicted to represent Tacky's friends. To signify its degrading quality, this penguin that is hiding behind a block of ice is presented small and almost unnoticed.

As can be seen in Figure 10, the visual elements in Tacky the Penguin are picked up in the verbal aspects through the intersemiotic complementarity relations of
Repetition (e.g., slapping on one's back), Synonymy (e.g., Tacky, hunters), and Collocation (e.g., Lovely, Perfect, etc.). These relations consistently realise the represented participants and processes but not the represented circumstance. How the presence of others (e.g., sneering reactions from other penguins, a threatening situation) incorporates potential threat and possibly intimidates Tacky is not stated explicitly in the verbiage. Here, the message about potential intimidation for Tacky is a gap that the readers need to fill based on the visual clues.

\begin{tabular}{|c|c|c|c|c|c|c|c|c|}
\hline \multirow{2}{*}{$\begin{array}{c}\text { Text sources } \\
\text { VMEs }\end{array}$} & \multicolumn{8}{|c|}{ Message elements } \\
\hline & Tacky & $\begin{array}{c}\text { One } \\
\text { hunter }\end{array}$ & Hunters & $\begin{array}{c}\text { Slapping } \\
\text { on one's } \\
\text { back }\end{array}$ & $\begin{array}{c}\text { Baffled } \\
\text { look }\end{array}$ & hiding & $\begin{array}{l}\text { Saying } \\
\text { loudly }\end{array}$ & $\begin{array}{c}\mathrm{A} \\
\text { threatening } \\
\text { situation }\end{array}$ \\
\hline Text D1 & Tacky & & & & & & blared & \\
\hline Text D2 & & $\begin{array}{c}\text { one } \\
\text { hunter }\end{array}$ & & $\begin{array}{c}\text { slap on } \\
\text { the back }\end{array}$ & & & & \\
\hline Text E1 & & & they & & & & & \\
\hline Text E2 & penguin & we & we & Penguins & & & & \\
\hline $\begin{array}{l}\text { Complimentarity } \\
\text { notes: }\end{array}$ & synonymy & sy nonymy & sy nonymy & repetition & & & sy nonymy & \\
\hline
\end{tabular}

Figure 10. Ideational-intersemiotic complementarity of an attempted solution

Through intersemiotic complementarity analysis, the reading of this picture book can be more accessible for EFL students. In the classroom, discussions with the students can be concerned initially with the messagefocus aspects of a visual such as what or who is represented in the pictures, what they are doing, and how they are doing it or who/what they are doing it with. Talking about the visuals can be less threatening for EFL students as it can be done in their first language. Then, the focus is extended to see whether the visuals represent what is stated verbally and identify the kinds of relations emerging from the two modes. The students' prior identification of the ideationalrepresentational aspects can be used as a springboard to decode English words in the written texts, which will be useful for the EFL students' development of English literacy. Moreover, as it is argued by Royce (2007b), the shift of concentration on either the visual or verbal, to a view of the text as an interaction between them can also support the development of EFL students' multimodal communicative competence.

\section{Page-by-page information value arrangement}

Before moving on to mapping the reading path, it is necessary to identify the semiotic resources involved on a page or spread of a picture book; that is, colour and typography. It is observable that Tacky the Penguin employs colourful images and typographic written language. In terms of colour, white is used as the predominating colour for the background. The use of white as the background plays two roles. First, it separates the background and foreground images. Secondly, the use of vivid colours for the characters creates a clear distinction between each of the characters.

The use of black for the typography stands out on each page. In this way, it is clear that the primary semiotic resources in the picture book consist of a form of typographic written language and colourful images. It is also worth noting that some images use strong framing in the form of square black lines. This frame functions to focus readers' attention on the scene presented within the frames. The discussion of the reading path on a page-by-page basis is made following the flow of these semiotic resources.

The first identified arrangement is a central layout. Of the three data sets (as presented earlier in Method section, Figures 2-4), Tacky, the main character, is put at the most prominent locus in the centre of the page. This arrangement takes the readers to focus on the content of the page from two directions. First, readers may be fixated on the image resources of Tacky at the centre of the page. Then, this image becomes the ideal information that readers encounter before moving onto the information given as the written language at the bottom of the page.

While the study does not focus on the genre structure in Tacky the Penguin, the analysis encounters the presumed functions of Orientation and Evaluation that may be contributed by the layout of the languageimage resources. The first data set-the spread displayed in Figure 2, presents the storyline in topbottom image-language arrangements. Here, readers are familiarised with the background image, main characters, and, most importantly, oriented to the characterisations. Similarly, the second data set-the page in Figure 3, employs top-bottom image-language 
arrangements. Hence, the image placed on the top of the verbiage functions to signify Tacky's way of greeting, which is different from other penguins' depicted in the earlier part of the book.

The third data set - the spread in Figure 4, presents an attempted solution of the story where Tacky's unique greeting is depicted as a way to deal with the hunters. It employs not only top-bottom language-image arrangements but also alternate layout arrangements of language and image arrangement.

Figure 11 illustrates the top-bottom languageimage arrangements that put the language at the more prominent space, which is at the top of the page, compared to the image element, which is now positioned at the bottom. In this way, it is presumed that the images have been used to engage the readers with familiarity towards the characters in the first half of the book.

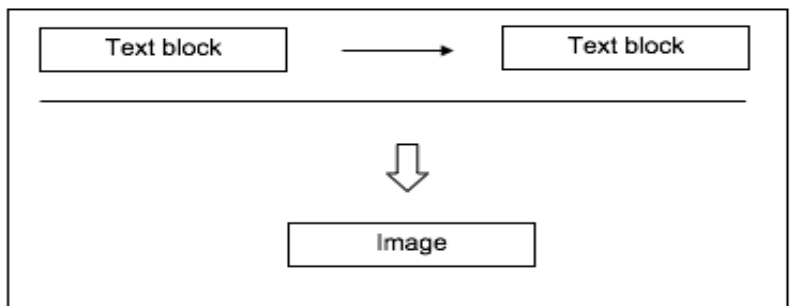

Figure 11. The first possibility of the reading path in spreads

Figure 12 displays the second possible reading path that shows alternate layout arrangements of language and image resources. In the verso of the spread, language resource is put at the very top of the page, followed by images, then followed by another language resource. This pattern continues to the recto of the spread; only this time, the language and image resources are put in a zig-zag arrangement. Nevertheless, they both realise the top-bottom structure. In contrast to the first spread (Figure 2), the focus of the second spread (Figure 4) shifts by taking the readers in to the twist of what is initially considered annoying for the penguins (displayed on the verso) becomes a life-saving act for them (on the recto).

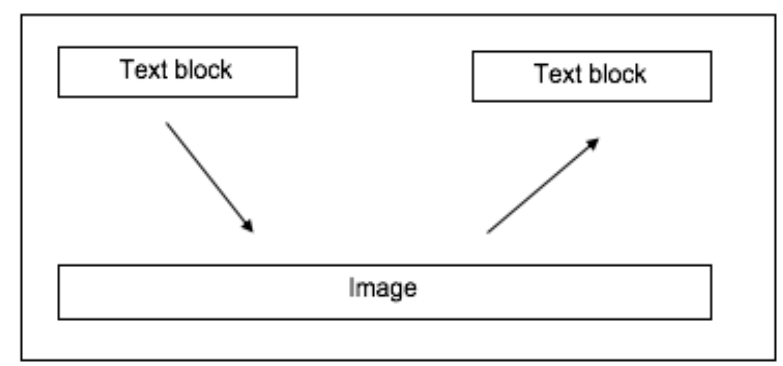

Figure 12 . The second possibility of the reading path in spreads

In terms of a general reading path, Figure 12 illustrates the reading path that begins either at the cover or the first page of the book, taking the readers in a conventional reading direction starting from the left. Within the pages, as can be seen in Figure 13, readers may encounter two types of general arrangements.

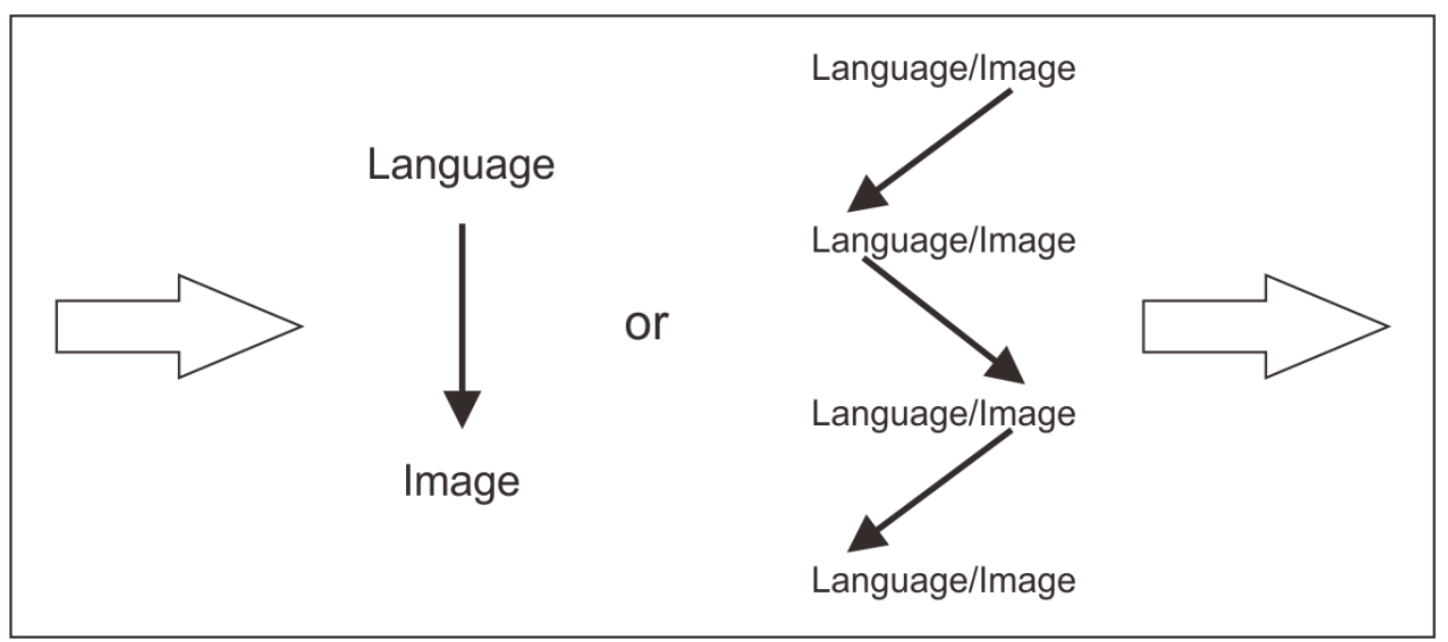

Figure 13. A general mapping of the reading path in TP

First, readers may gain information from the top of the page then flow to the bottom of the page. Alternatively, some information is presented in zig-zag arrangements where language or image at the top of the page then continued with another set of language or image, and so on. The reading path ends at the conclusion of the story on the final page of the book. The conventional left-to-right reading path provides a predictable move to understand the storyline. The dynamics of the arrangement within the book, on the other hand, gives the readers an experience of engaging with the contents of the book by following the language-image layout in the book.

\section{Pedagogical implications of the reading path in the picture book}

A recent study indicates that teachers' reflection of the use of images in textbooks is still restricted to focusing on the use of images as resources contributing to context introduction, interest engagement, illustration, 
or simply for decoration purposes (Vu \& Febrianti, 2018 , p. 289). While the current study reported in this paper does not obtain information from an empirical classroom action research, the theoretical investigation in the study provides sufficient information to draft the formulation of the pedagogical implication about its practical use in the classrooms. Three pedagogical implications are listed as follows.

a. Determining the starting point in using picture books in the classroom.

The understanding of the basic concept of the reading path in the picture book will inform teachers of the point of departure of the picture book discussion. Depending on the level of students, either language or image in the picture book can be the starting point of discussion in the classroom. For example, with low level or young students, images can be a good starting point to arouse their interests in the picture book activity. Students at the intermediate level might start reading from the language resource to understand the flow of the story. In this case, the images are supplementary. Students at the advanced levels may be capable of discussing the picture book page by page or spread by spread, accounting for both resources.

b. Utilising visual and image resources in the books to discuss meanings.

In the EFL context, discussing meanings of words is often one of the essential concerns in language teaching and learning activities. Language and image in the picture books are rich resources that can be utilised for this type of activity. When intersemiotic relationships allow, direct relations can be drawn from the literal use of language to gloss the image. Otherwise, both language and images can be discussed to build students' glossary in order to understand the story in the picture book.

c. Motivating talk-around-text activities.

In addition to the given story, which is unfolded through language and image resources, picture books are potential for content-based discussions. While language and image are provided in the picture book for literal comprehension of the story, talkaround-text often arise as a result of the probe inside the surrounding context of the story. For example, a story like Tacky the Penguin may spark interest in the discussion of penguin, icy lands, global warming, or relating to real-life situations by talking about the cases of differences in people's characters, cases of bullying as an example.

In sum, supporting students' understanding of a story could be developed not only from the identification of characters and plot structures in the verbal texts but also from the examination of visual representation and visual narrative sequence.

\section{CONCLUSION}

The study has shown that the reading path is structured by, among others, the interrelations between the language and image as well as the flow of information value in the children book. In the case of the observed picture book, the combination of both linear and nonlinear reading paths is found. Such a combination provides a safe ground to predict that readers may employ both linear and non-linear reading paths in approaching the semiotic resources presented in the picture books. This means that while picture books may be designed by the author with a determined linear reading path. The decision to approach the picture book remains an exclusive choice of the readers. In this case, readers can decide to approach the texts in the picture books in both linear and non-linear ways.

One of the drawbacks of the study is the fact that only one book was used as the main data source. A corpus of children books can be used as a source of data for further study. Also, considering that the study is done in Indonesia, it will be worth investigating to use Indonesian children's books as comparative data. This study is a preliminary study to introduce the theoretical grounds on which the mapping in the story reading is structured via the information value and the interrelatedness of language and image in the book. Further studies can be directed into the practical implications of trials with students in the classrooms and children as readers. In school contexts, it is also possible to develop the study to include the understanding of the composition and intersemiotic complementarity in school textbooks.

\section{REFERENCES}

Bateman, J. A. (2014). Text and image: A critical introduction to the visual/verbal divide. New York: Routledge.

Christie, F., \& Derewianka, B. (2008). Writing stories in subject English. In F. Christie, \& B. Derewianka, School discourse: Learning to write across the years of schooling (pp. 30-57). London: Continuum International Publishing.

Damayanti, I. L. (2014). Gender construction in visual images in textbooks for primary school students. Indonesian Journal of Applied Linguistics, 3(2), 100-116.

Halliday, M., \& Hasan, R. (1985). Language, context, and text: Aspects of language in a social-semiotic perspective. Deakin, Vic: Deakin University Press.

Halliday, M., \& Matthiessen, C. (2014). An introduction to functional grammar (4th ed.). Oxon: Routledge.

Hermawan, B., \& Sukyadi, D. (2017). Ideational and interpersonal meanings of children narratives in Indonesian picturebooks. Indonesian Journal of Applied Linguistics, 7(2), 404-412. 
Kress, G. R., \& van Leeuwen, T. (1996). Reading images: The grammar of visual design (1st ed.). London: Routledge.

Kress, G. R., \& van Leeuwen, T. (2006). Reading images: The grammar of visual design (2nd ed.). London: Routledge.

Lee, H. (2015). Using picture books in EFL college reading classrooms. The Reading Matrix, 15(1), 66-77.

Lester, H. (1988). Tacky the penguin. Boston: Houghton Mifflin .

Mourão, S. J. (2016). Picturebooks in the primary EFL classroom. Children's Literature in language Education Journal, 3(2), 25-43.

Oe, Y., \& Alam, Y. S. (2013). Picture-based e-learning of English phrasalverbs: A comparative study of the use of pictures and L1 glosses. Journal of Humanities \& Arts Computing: A Journal of Digital Humanities, 7, 222-233.

O'Halloran, K. L., Marissa, K. L., Podlasov, A., \& Tan, S. (2013). Multimodal digital semiotics: The interaction of language with other resources. Text \& Talk, 33(4-5), 665-690.

Painter, C., Martin, J., \& Unsworth, L. (2013). Reading visual narratives: Image analys is of children's picture books. Sheffield: Equinox Publishing Ltd.

Royce, T. D. (1998). Synergy on the page: Exploring intersemiotic complementarity in page-based multimodal text. JASFL Occasional Papers, 1(1), 25-49.

Royce, T. D. (2007a). Intersemiotic Complementarity: A framework for multimodal discourse analysis. In T. D. Royce, \& W. L. Bowcher, New directions in the analysis of multimodal discourse (pp. 63-109). New Jersey: Lawrence Earlbaum Associates, Inc.

Royce, T. D. (2007b). Multimodal communicative competence in second language contexts. In T. D. Royce, \& W. L. Bowcher, New directions in the analysis of multimodal discourse (pp. 361-390). New Jersey: Lawrence Erlbaum Associates, Inc.

Sun, C. H. (2015). The three little wolves go to college: A picture book lesson for young adult EFL learners. Journal of Adolescent \& Adult Literacy, 59(2), 183-195.

Unsworth, L., Cope, J., \& Nicholls, L. (2019). Multimodal literacy and large-scale literacy tests: Curriculum relevance and responsibility. Australian Journal of Language and Literacy, 42(2), 128.

Vu, T., \& Febrianti, Y. (2018). Teachers' reflections on the visual resources in English textbooks for Vietnamese lower secondary schools.TEFLIN Journal, 29(2), 266-292. doi: 10.15639/teflin journal.v29i2/266-292 